\title{
AOR
}

Selected Papers of \#AolR2018:

The $19^{\text {th }}$ Annual Conference of the Association of Internet Researchers Montréal, Canada / 10-13 October 2018

\section{INTIMACIES AND DIGITAL MEDIA INFRASTRUCTURES}

\author{
Sander De Ridder \\ Ghent University \\ Frederik Dhaenens \\ Ghent University \\ Stefanie Duguay \\ Concordia University \\ Lindsay Ferris \\ University of Oxford \\ Susanna Paasonen \\ University of Turku
}

The breadth of what it means to study intimacies in the context of media has changed significantly in recent years because of current technological, social, and cultural changes. The shift from one-to-many to many-to-many communication infrastructures has multiplied the institutional, technological, and symbolic dimensions that need to be taken into account when inquiring into sexuality, gender, intimacy and media, cultures and communications. The digitization of intimacies - which refers to changing attitudes, experiences, and practices to intimacy because of digital media - demands that scholars look beyond the well-established frameworks to study intimacy and media, expanding their methodological and theoretical perspectives in order to fully comprehend intimate life-worlds and the digital.

The contributions in this panel are seeking to advance the understanding of the experiences and politics of intimacy and diversity in the context of the materiality of digital media (including affordances, algorithms, and the politics of social media platforms and data). It wants to make a theoretical, conceptual, and empirical contribution to the field by exploring how techno-cultural and socioeconomic aspects of digital media infrastructures are intertwined with intimacies. The contributions to this panel are inquiring into diverse digital media platforms (Facebook Messenger, Dating 
applications and a specific focus on Tinder and the video-sharing platform YouTube), exploring feelings, identities, visibilities and normativities surrounding the spheres of intimacy and gender.

The transformation of intimacies because of digital media infrastructures is traditionally valued in either positive or negative terms, the contributions to these panel seek to rework these assumptions. Examples of distinctly positive claims are presumed increases in digital safe spaces where sexual minorities can interact (e.g., on gay dating apps such as Grindr), and ideas that digital media are providing new and more opportunities for voicing non-normative gender identities (e.g., on video-sharing platforms such as YouTube). An example of a negative claim is that the Internet also increases sexual risks, particularly for children and young people. The panel wants to move beyond anecdotal evidence and moral claims by developing analytical approaches that understand the material complexities of digital media in relation to people's intimate life-worlds. Therefore, the contributions to this panel are using various in-depth research methodologies such as textual analysis, interviews and ethnography. Using thick descriptions allows to expose the often unseen digital media infrastructures that run underneath, through, and in the background of intimacies. By conceptualizing the emerging struggles that are inherent to the accelerating digitization of intimacy, we want to explore what is changing/continuing.

If digital media infrastructures are important to people's intimacies, there is a need to engage with the question of how and why they matter. Do the techno-cultural and socioeconomic aspects of digital media create flourishing and diverse sexual life-worlds and as such allow more fluid sexual imaginaries? How are sexual displays strictly regulated on different platforms, while they are at the same time widely shared? How do people value seeking intimacy trough digital media, and why is it often problematized? How do digital mainly genres constructing genders?

Engaging with these questions, the panels seeks to provide rich and textured insights, as well as initiate further debate on the multiple relations between people's intimacies and digital media infrastructures. 


\section{GLORY HOLES IN THE INFRASTRUCTURES OF INTIMACY}

\section{Susanna Paasonen}

University of Turku

Ubiquitous connectivity through apps and social media is not merely an instrumental, mediating factor or "the channel" in and for intimate attachments but a sociotechnical affordance that supports and modulates them (cf. Wilson 2016, 249; Author 2018). Everyday lives are lived, and intimacies surface and wither, in networks composed of human and nonhuman actors in ways that are far from being metaphorical. These networks both facilitate and condition the myriad forms that sexual titillations, desires, attachments and experimentations continue to take. These infrastructures are corporate by default, and the data that user exchanges generate function as key resource and fuel within the overall economy of social media.

Bringing together this notion of social media as socio-technological infrastructures of intimacy together with the rather literal figure of the glory hole, this paper sets out to address the ubiquitous yet ambivalent place of sexual displays and exchanges in social media. It argues that the seeming incompatibility between corporate codes of appropriate content and conduct, as articulated in services' terms of use, and the routinely sexual, inappropriate lines that exchanges between users take results in the dynamics of peek-a-boo where sexual user-generated content is both filtered and flagged out of public view and permanently present on and facilitated by backchannel exchanges. Using the example of the dick pic as prime example, this paper then inquires after their politics of visibility and invisibility within the infrastructures of social media.

Glory holes are user-generated and communally maintained infrastructural features of public sex, as in the context of anonymous gay male bathroom sex (on cottaging, see Light 2016; Wilson 2016, 254). Carved onto walls meant to separate people in various degrees of undress, they allow for occasions "of mutual enjoyment and affective intensity among otherwise unlikely intimates or partners" (Race 2014, 7). Glory holes allow for both physical contact and pleasures of looking and being seen. With glory holes, I am here however not referring to subversive hacking that give rise to instances of sexual freedom and unruliness rupturing corporate framework in social media. Rather, I argue that, in addition to being knowingly sought out and crafted by users, they come inbuilt in the services used.

Social media services' terms of use are formulated in accordance with values and norms compatible with the desires of advertisers and the corporate public image that the platform wishes to uphold. This involves a ban on publishing sexually explicit content on Facebook or Instagram but does not extend to private exchanges through Facebook Messenger or WhatsApp owned by the same company. In this sense, Messenger functions as the glory hole in the architecture of Facebook.

Paasonen, S. (2018, October 10-13). Gloryholes in the infrastructures of intimacy. Paper presented at AolR 2018: The $19^{\text {th }}$ Annual Conference of the Association of Internet Researchers. Montréal, Canada: AolR. Retrieved from http://spir.aoir.org. 
Glory holes facilitate exchanges cutting through presumed divides between the public and the private - as in the privacy of a booth in a public bathroom that the hole turns into a shared space. Such encounters can be sought out in eager anticipation but a penis may also well intrude into one's booth unanticipated and undesired. The case is similar with the dick pic as a symbolic depiction of genitalia that has gained something of ubiquitous presence on social media. Dick pics are used as instruments of visual harassment in organized trolling campaigns and misogynistic personal attacks against, sent to potential sexual partners and displayed as advertisements of corporeal assets on dating apps, as well as shared for the purposes of humour, diversion and selfexploration (e.g. Tiidenberg and Cruz 2015; Author \& al. forthcoming). Journalistic accounts of women fighting back harassment by publishing the unsolicited dicks pics from social media backchannels have been abounding, as have Tumblr galleries dedicated to the art of the dick pic. Like penises sticking through glory holes, dick pics can be solicited or unsolicited, objects of pleasure or aversion, instruments for violence and intimacy in contexts straight and queer.

While self-shooting facilitated by mobile phones has, in combination with the ease of sharing the outcome, fuelled dick pic creation and the overall cultural presence of such imaging practices, it would be erroneous to consider them as unique to the current moment. Dick pics were sent for decades in readers' letters to porn magazines for the thrill of them being potentially published and as standard features in gay online dating well before the uses of apps (Author $\&$ al. forthcoming). Their social circulation has accelerated in networked media both in terms of volume and the diverse ends that they are put into. Special spaces are allocated for dick pics in social media, from platforms such as Tumblr and Twitter allowing for the public sharing of sexual content to the backchannel options of Messenger, WhatsApp and Snapchat.

Following Lauren Berlant $(2000,4)$, intimacy is a matter of "connections that impact on people, and on which they depend for living". Considered as an infrastructure of intimacy, social media affords and shapes connections and disconnections as ones involving more than merely human parties: devices, apps, platforms and algorithms all impact on people, and they are all depended on for living. As Ara Wilson $(2016,270)$ points out, the prefix "infra" means "below" in ways indicating default invisibility or hiddenness. A critical focus on infrastructures of intimacy makes it possible to map out the avenues designed for their construction - such as Facebook relationship statuses, hearts, tags and backchannel exchanges - as ones of varying default visibility.

Exchanges through the glory hole of Messenger generate user data similarly to any other user activities on Facebook. As part of site and app architecture, the backchannel contributes to flows of user data allowing for its increased granularity, yet without offending third parties and commercial partners with any potential sexual explicitness. Since sexual interests and exchanges drive social media traffic, blocking them completely out would not only be impossible but bad for business. Deployed in the context of social media, the figure of the glory hole then shifts attention away from the intentions and experiences of people - as in instances of sending and receiving dick pics - towards the infrastructures that make such exchanges possible by design. Paasonen, S. (2018, October 10-13). Gloryholes in the infrastructures of intimacy. Paper presented at AolR 2018: The $19^{\text {th }}$ Annual Conference of the Association of Internet Researchers. Montréal, Canada: AolR. Retrieved from http://spir.aoir.org. 


\section{References}

Berlant, Lauren. 2000. Intimacy: A special issue. In Lauren Berlant (ed.), Intimacy. Chicago: University of Chicago Press, 1-8.

Light, Ben. 2016. Producing sexual cultures and pseudonymous publics with digital networks. In Rebecca Ann Lind (ed.), Race and Gender in Electronic Media: Content, Context, Culture. London: Routledge, 231-246.

Race, Kane. 2015. Speculative pragmatism and intimate arrangements: online hook-up devices in gay life. Culture, health \& sexuality 17, no. 4: 496-511.

Tiidenberg, Katrin and Cruz, Edgar Gómez. 2015. Selfies, Image and the Re-Making of the Body. Body \& Society 21, no. 4: 77-102.

Wilson, Ara. 2016. The infrastructure of intimacy. Signs: Journal of Women in Culture and Society 41, no. 2: 247-280.

Paasonen, S. (2018, October 10-13). Gloryholes in the infrastructures of intimacy. Paper presented at AolR 2018: The $19^{\text {th }}$ Annual Conference of the Association of Internet Researchers. Montréal, Canada: AolR. Retrieved from http://spir.aoir.org. 


\title{
THE DIGITAL LESBIAN IMAGINARY: INVESTIGATING (IM)PERMEABLE BOUNDARIES OF SEXUAL IDENTITY ON TINDER
}

\author{
Stefanie Duguay \\ Concordia University \\ Lindsay Ferris \\ University of Oxford
}

\section{Introduction}

There are women looking for women on the app that are not interested romantically in women. That's why there is a certain aspect of trying to look queer when you're on your Tinder Profile. - Jane (23, United Kingdom)

There's a three-stage thing to how confident I am that they're gay. If they have the then they have [Facebook] 'likes,' like [gay bars], then I'm like, "Probably." But if they're like outright, "Oh, I like girls" or they slip in that they're gay somewhere, I'm like, "Yep." - Danaë (19, Australia)

Jane and Danaë are referring to their difficulty discerning the sexual identity of others on Tinder, a popular dating app primarily marketed to heterosexual users. While individuals can change their search criteria to "men seeking men" and "women seeking women", this paper explores the insufficiency of these settings for women who identify as lesbian, gay, bisexual, transgender, and queer (LGBTQ) in their search for female-identified partners. The "women seeking women" setting allows for the formation of a public among LGBTQ women but this public is permeable to predatory men, couples, and heterosexual women. In response to this intrusion, LGBTQ women send clear signals of sexual identity to each other. They reference cultural symbols associated with lesbian identity, constructing a digital lesbian imaginary that makes their attraction to women easily recognizable. While this digital lesbian imaginary enables LGBTQ women to meet through a mainstream dating app, it also poses restrictions to the more fluid sexual and gender identities these women present in other publics.

\section{Digital and LGBTQ Imaginaries}

The concept of "digital imaginary" comprises the many ways that cultural referents combine with technological infrastructures to create new possibilities. With regard to shifting forms of communication, Hess and Zimmerman (1999) refer to "transnational digital imaginaries" as "suspended somewhere in-between the material realisitive of the current political era and our collective ability to radically reimagine different ways of thinking about, producing, and interfacing with visual works" (p. 150). They further describe the digital as refiguring "past/future traces," viewing digital media as opening Duguay, S., \& Ferris, L. (2018, October 10-13). The digital lesbian imaginary: Investigating (im)permeable boundaries of sexual identity on Tinder. Paper presented at AoIR 2018: The $19^{\text {th }}$ Annual Conference of the Association of Internet Researchers. Montréal, Canada: AolR. Retrieved from http://spir.aoir.org. 
possibilities for creating future cultural meanings - locally and across nations - while also drawing on current and past media and politics. Building on this perspective, Miller's (2014) speculative collection of imaginary apps illustrates how mobile apps are often software instantiations of metaphors and cultural tropes. Extending conceptualizations of technological affordances, Nagy and Neff (2015) define imagined affordances as emerging "between users' perceptions, attitudes, and experiences; between the materiality and functionality of technologies; and between the intentions and perceptions of designers" (p. 5). Our paper uncovers these imagined aspects of Tinder's infrastructure, as they combine with user intentions and cultural references to construct or transgress boundaries of sexual identity.

This paper also invokes imaginaries relating to stigmatized sexual identities. LGBTQ individuals have long operated in opposition to the heteronormativity of mixed spaces, signaling sexuality to each other in varying and covert ways (Green, 1997). For women attracted to women, these signals are ever shifting but align with particular fashion, behavior, politics, and co-situation within LGBTQ spaces to constitute an archetypical lesbian identity. It is through these cultural references and signals that LGBTQ women construct imagined, mutually shared sexual identities. As sexual identity becomes increasingly mediated, these signals also draw on digital features and functions, involving textual styles, email signatures, emoji, and images as digitally embodied references to sexual identity (e.g. Correll, 1995).

\section{Methods}

This paper combines findings from two similar studies of LGBTQ women's use of Tinder. One author interviewed ten women in Australia and Canada while the other author interviewed seventeen women in the United Kingdom (UK). During these semistructured interviews, participants led the researcher through their Tinder profiles and various apps screens, following procedures similar to Jørgensen's (2016) media goalong method. Taken together, these 27 participants varied in age from $19-35$, sexual self-identification (e.g., lesbian, gay, queer, pansexual, homoflexible), and gender identity. Although all were female-identified, several identified as genderfluid, presenting varying degrees of masculinity or femininity. Since the interviews followed a similar structure and criteria for participant recruitment, analyzing them together allows for the triangulation of findings (Hammersley, 2013). While these studies present a transnational analysis of LGBTQ women's Tinder experiences, their focus on westernized countries presents both a limitation and opportunity for future research with regard to extending our findings to other cultures and locations.

\section{Findings and Discussion}

Upon selecting "women seeking women" on Tinder, our participants viewed themselves as entering a separate public for LGBTQ women. Elizabeth (26, UK) described a scarcity of physical meeting places for LGBTQ women, noting that "apps like this, where you have to swipe to meet people, were the places where [women she knew] met."

Duguay, S., \& Ferris, L. (2018, October 10-13). The digital lesbian imaginary: Investigating (im)permeable boundaries of sexual identity on Tinder. Paper presented at AoIR 2018: The $19^{\text {th }}$ Annual Conference of the Association of Internet Researchers. Montréal, Canada: AolR. Retrieved from http://spir.aoir.org. 
Despite this utility, participants expressed frustration with deceptive profiles belonging to men or couples soliciting sexual messages, photos, and hookups. Julia (28, Australia) recounted multiple run-ins with "catfishing" users, who she described as "someone who's a fake, a guy pretending to be a girl or something." Subtler than catfishing accounts were the women Jane references in the opening quote, who were "bi-curious" or looking for friends. To contend with the permeation of these users, participants played what Alex $(21, \mathrm{UK})$ called the "guessing game of who is legitimately gay and who is not."

Participants signaled their "legitimately gay" sexual identity by combining Tinder's imagined affordances with symbols of an imagined, shared lesbian identity. They referenced lesbian-associated popular culture, such as the television show Orange is the New Black, and - through Tinder's visual emphasis and connection with Facebook displayed lesbian fashion, affiliation with lesbian-related locales, and symbols including

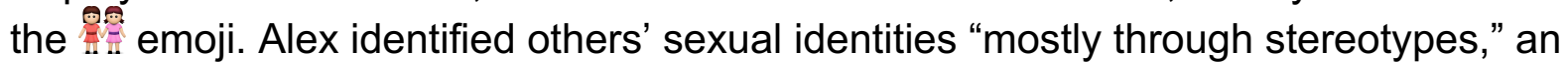
approach that resonated with most participants. Despite interchangeably referencing gay, lesbian, queer, and other sexual identities in interviews, participants' combination of Tinder's imagined affordances with longstanding references to lesbian culture instantiated a digital lesbian imaginary on Tinder.

Those who did not present these signals were subject to questioning from other women over their intentions. Chloe (27, UK), who describes herself as "queer femme," explained, "It's frustrating when people ask me if I identify as straight when clearly I don't." The widespread practice of incorporating Tinder's features to quickly signal lesbian identity contributed to the erasure of other identities in this public. These findings highlight how a dating platform's infrastructure and user practices combine to narrow the diversity of representational norms rather than allowing for more fluid sexual imaginaries.

\section{References}

Correll, S. (1995). The ethnography of an electronic bar: The Lesbian Cafe. Journal of Contemporary Ethnography, 24(3), 270-298.

Green, J. (1997). Language: Polari. Critical Quarterly, 39(1), 127-131.

Hammersley, M. (2013). What is qualitative research? London: Bloomsbury.

Hess, J., \& Zimmermann, P. R. (1999). Transnational digital imaginaries. Wide Angle, 21(1), 149-167.

Jørgensen, K. M. (2016). The media go-along: Researching mobilities with media at

Duguay, S., \& Ferris, L. (2018, October 10-13). The digital lesbian imaginary: Investigating (im)permeable boundaries of sexual identity on Tinder. Paper presented at AoIR 2018: The $19^{\text {th }}$ Annual Conference of the Association of Internet Researchers. Montréal, Canada: AolR. Retrieved from http://spir.aoir.org. 
hand. Journal of Media and Communication Research, 60, 32-49.

Miller, P. D. (2014). Preface. In P. D. Miller \& S. Matviyenko (Eds.), The imaginary app (pp. ix-xv). Cambridge, MA and London: MIT Press.

Nagy, P., \& Neff, G. (2015). Imagined affordance: Reconstructing a keyword for communication theory. Social Media + Society, 1(2), 1-9.

Duguay, S., \& Ferris, L. (2018, October 10-13). The digital lesbian imaginary: Investigating (im)permeable boundaries of sexual identity on Tinder. Paper presented at AoIR 2018: The $19^{\text {th }}$ Annual Conference of the Association of Internet Researchers. Montréal, Canada: AolR. Retrieved from http://spir.aoir.org. 


\title{
DATING AND DATAFICATION: FEELINGS OF TECHNOLOGICAL DEPENDENCE
}

\author{
Sander De Ridder \\ Ghent University
}

Dating applications on smartphones (e.g. Tinder, Happn, Grindr) are based on the automated accumulation, sorting and interpretation of data; they allow people to connect. As they are becoming increasingly popular to use, dating apps are embedded into many people's everyday intimate connections. The automation of data processing is a significant evolution in the social construction of intimacy, which is becoming increasingly dependent on media technologies and its institutions (Couldry and Hepp, 2017). As dating apps are domesticated into the everyday lives of people, these "personal digital data assemblages" (Lupton, 2016) are deeply meaningful, constituting affective, sensory and practical infrastructures that are making intimate connections possible (Pink et al., 2017).

This contribution is interested in the personal and experiential ways dating apps both emerge and are implicated into people's intimacies. Drawing on ethnographic research in the city of London (Kitchin and Dodge, 2011; Pink, 2009), involving 10 young adults between 18 and 30 years old, this presentation focuses people's affective attachments to the presence of dating apps in their everyday life worlds. The data consists of deep conversations with participants (lasting between 90 minutes up to two hours), focusing on the cognitive and emotional aspects of datafication; how they are experienced between human interpretation and particular algorithmic processes, but also in relation to the environment such as the cosmopolitan context of London. It draws on how intimate and sexual lives in large cities is, by default, characterized by intense (digital) communication, difference and diversity, but also loneliness and continuous change.

Drawing on the European cultural studies tradition of audience research (Ang, 1985; Morely, 1992) this contribution does not seek to merely understand people's individual affective attachments to direct uses of dating applications, but rather aims to grasp the datafication of intimacy as a collective experience among people living in shared temporal and spatial life worlds. Lynn Jamieson's (2011) description of intimacy, she explores intimacy from a perspective of "global change" and within "cross cultural contexts", is used as a conceptual lens. For Jamieson, intimacy refers to "the quality of close connection between people and the process of building that quality"; which allows this contribution to ask the question of how people value the datafication of dating and intimacy in relation to building intimacy and closeness.

The participants in this ethnographic study had arrived in London for less than four years, sharing the experience of being a university student or a young professional. The participants responded to a call which was distributed by a major London university to students and recent graduates. The call invited people who wanted to share stories about

De Ridder, S. (2018, October 10-13). Dating and datafication: Feelings of technological dependence. Paper presented at AolR 2018: The $19^{\text {th }}$ Annual Conference of the Association of Internet Researchers. Montréal, Canada: AolR. Retrieved from http://spir.aoir.org. 
dating applications, stating they could be a current user of dating applications or not, as shown in the following fragment from the call.

"Participants can be those who love using dating applications, hate them, need them, have been using them, or maybe never will. You can be a 'heavy' daily consumer, or not; maybe these apps are very present in your life-world, without you using them (but you still have something to say about them)."

The findings and discussions draw on five participants that were actual users of dating applications, two participants that had been using dating applications but stopped using them, and three who never used dating applications but had many things they wanted to share about them.

A primary way for understanding the collective experiences that bounded each participant together was a reflection on their needs (in various degrees and in diverse constellations) to build close intimate connections in London. Those that used dating apps were able to have an always available connected presence with potential close connections, securing them from destabilizing feelings of loneliness; as such dating apps are seen as providing a sense of "ontological security" (Giddens, 1994). Dating app users valued the datafication of dating because it allowed them to accommodate to their various needs; from carefully using match making algorithms to find 'the one', to seeking casual (sexual) encounters afforded by playful matching games based on nearby location and a profile picture. The datafication of dating means that seeking intimate connection is organized by an "objectification contract" (Wark 2017); algorithms provide a service accommodating various needs for intimate connection that users must learn to navigate.

Those participants that did not use dating apps morally disapproved of such an objectification contract (it threatened "authentic intimacy"), or some argued the datafication of seeking intimacy is simply "too intense" to navigate. I argue how these moral opinions on datafied dating are related to how non-users of dating apps were overwhelmed by a feeling of dependence on dating apps; they felt as having no choice anymore but to commit themselves to an objectification contract organized by dating applications. The feeling of being overwhelmed by the ubiquitous presence of dating apps was connected to how not using dating applications means not having the ontological security they provided to people that did use them. Dating applications are being seen as necessary resources to navigate closeness in cosmopolitan London.

This contribution concludes with making a theoretical contribution. When the participants argued they felt dependent on the logic of data processing to find intimacy, this was connected to having strong (negative) moral opinions on the use dating applications. Such feelings of dependence are showing how datafication processes matter greatly in the intimate lives of people. Moreover, these feelings of dependence are illustrative of the cultural power of datafication processes; it shows how they are reshaping the values of what building "good" intimacies means in deeply mediatized societies.

De Ridder, S. (2018, October 10-13). Dating and datafication: Feelings of technological dependence. Paper presented at AolR 2018: The $19^{\text {th }}$ Annual Conference of the Association of Internet Researchers. Montréal, Canada: AolR. Retrieved from http://spir.aoir.org. 


\section{References}

Ang, I. (1985) Watching Dallas: Soap Opera and the Melodramatic Imagination. London: Methuen.

Couldry N. and Hepp A. (2017) The Mediated Construction of Reality. Cambridge: Polity.

Giddens, A. (1994) Modernity and Self-identity: Self and Society in the Late Modern Age. Cambridge: Polity Press.

Jamieson, L. (2011). Intimacy as a Concept: Explaining Social Change in the Context of Globalisation or Another Form of Ethnocentricism? Sociological Research Online 16(4). http://www.socresonline.org.uk/16/4/15.html

Kitchin R. and Dodge M. (2011) Code/Space. Software and everyday life. London: The MIT Press.

Lupton D. (2016) Foreword: Lively Devices, Lively Data and Lively Leisure Studies. Leisure Studies 35(6): 709-711.

Morely, D. (1992) Television, Audiences and Cultural Studies. London: Routledge.

Pink S. (2009) Doing Sensory Ethnography. London: Sage.

Pink S. Sumartojo S, Lupton D, et al. (2017) Mundane Data: The Routines, Contingencies and Accomplishments of Digital Living. Big Data \& Society 4(1): 2053951717700924.

Wark, M.K. (2017) General Intellects. New York, NY: Verso.

De Ridder, S. (2018, October 10-13). Dating and datafication: Feelings of technological dependence. Paper presented at AolR 2018: The $19^{\text {th }}$ Annual Conference of the Association of Internet Researchers. Montréal, Canada: AolR. Retrieved from http://spir.aoir.org. 


\title{
(UN)COVERING MASCULINITIES IN COVER SONG VIDEOS
}

\author{
Frederik Dhaenens \\ Ghent University
}

Even though the practice of covering popular songs is far from new, the increased availability of accessible video capture software and the ability to upload home-made videos on video sharing websites has encouraged music fans and aspiring amateur performers to share their cover song videos. The popularity of the practice, however, has led to the development of an Internet genre with its own set of normative conventions (Kavoori 2011). To understand the gendered dimensions and meanings of this practice, I conducted a qualitative study that explored the way gender is being articulated in the songs, videos and on the platform.

Taking notice of the fact that many young men produce cover songs videos of mainstream pop songs in domestic spaces, I examined how young male amateur performers negotiate these stereotypically 'feminine' spaces, media texts and practices. As popular music scholars (Biddle \& Jarman-Ivens, 2007) have demonstrated, popular music culture is heavily gendered. Different discursive practices ensure that a hierarchical gender order is upheld in popular music culture, demonstrated in the underrepresentation of women in various branches of the music industry or the gendering of genres and music instruments. A glaring contrast is the way pop and rock are framed and experienced as opposites, shaping pop music as categorically feminine and rock masculine (Coates 1997). Yet, what happens to the reiteration of gender hierarchies when we take into account the practice of cover songs in itself and its mediation on and transformation via YouTube?

To this end, I conducted a qualitative analysis of the YouTube channels of five cisgender amateur performers. The selection was based on the following criteria: the performers are engaged in producing cover song versions of 'popular' music artists; they produced at least ten videos; they vary from one another in terms of popularity and professionalism. Even though the selection has no intention in being fully representative, it allows to understand the diverse and similar ways masculinity is being negotiated in the popular media practice. Drawing on the results of this analysis, I argue in this paper (a) why the genre of cover song videos may be able to challenge a hegemonic masculine ideal (Connell, 2005) and (b) how this practice and platform enables, shapes and restrains the performance and representation of masculinities. To understand how gender is negotiated in the Internet genre of the cover song video, I start by pointing out how cover songs are able to highlight the gendered dimension of popular music culture. The value of a cover song resides in the artistic interpretation. Even though the alterations may vary, it is considered crucial that the cover song features an explicit recognition and negotiation of the original song. A common alteration concerns gender, where men perform songs by women and vice versa (Plasketes, 2005). The gender bending in cover songs should not be taken lightly, as Halberstam (2007) pointed out how cover songs may be an importance source for Dhaenens, F. (2018, October 10-13). (Un)covering masculinities in cover song videos. Paper presented at AolR 2018: The $19^{\text {th }}$ Annual Conference of the Association of Internet Researchers. Montréal, Canada: AolR. Retrieved from http://spir.aoir.org. 
queerness. She considers that covering allows one to revisit a musical past to look for modes to articulate queer affect and resistance to heteronormativity. She stresses that cover songs should not per se be an ironic appropriation as cover artists often express a sincere affection and respect for the originals even though they reimagine the song by altering genre, lyrics or singing voice. The ability of cover songs to deconstruct the gender order resonates well with Taylor's (2012) perspective on popular music culture to reach out to people who are unable to express their sexual or gender identities in their everyday-lives. Whereas nonnormative identities are generally repressed in public, popular music culture offers various means for self-identification and community formation around nonnormative gender and sexual identities.

Besides more obvious genres such as coming out videos and slash fiction videos, I argue that the cover song video genre demonstrates Taylor's argument through its challenges to a hegemonic masculine ideal, despite the creation of normative conventions. Amateur performers on YouTube are aware of its potential to transform them into stars (Kavoori 2001). Achieving symbolic capital thus depends on choices involving the regulating and marketing of the self, which Van Dijck (2013) underscores as something young people experience as normal in their everyday-lives. Like with any identity profile on social media, amateur performers present a paradoxical identity. On the one hand, they stress the authenticity of them being as ordinary as their own followers and fans but, on the other, claim control over how they represent themselves 'as authentic', which involves the choice of songs, setting, outfits, attitude and the amount and kind of biographical snippets they share. The choices made are not random. They result from careful negotiations of what kind of authentic identity the performers want to portray, often based on the practices of other producers of cover song videos.

Yet, these shared conventions does not imply a similar performance of masculinity. Looking at the young male performers in our sample, we notice a variety of masculinities. Even though the sample consists of cisgender men, they perform divergent masculinities that are situated on a continuum between queer masculinities and more traditional masculinities. Yet, none of them reiterates a masculinity that is legitimated in contemporary Western society as superior to other men or women. Nor are they engaged in policing the masculinity of other performers or fans. They welcome praise on their music and looks by male and female fans. Further, even though few men explicitly represent themselves as queer or part of the LGBTQ community, many cover songs by openly LGBTQ artists such as Sam Smith or Troye Sivan, perform in 'feminized' spaces such as the living room or bedroom, and rarely underscore a heterosexual identity. Last, the platform offers a space for young men to represent nonnormative masculinities through music and cover song videos while the videos on their own provide representations to audiences who are looking for role models who do not adhere to a hegemonic masculine ideal. Even though the masculinities correspond to what Van Dijck has described as paradoxical, with a performance of a sincere and fragile masculinity in a domestic setting as the videos' main trope, they nonetheless help establishing processes of identification. As many comments to the YouTube videos reveal, their active audiences applaud the various expressions of masculinity. Few Dhaenens, F. (2018, October 10-13). (Un)covering masculinities in cover song videos. Paper presented at AolR 2018: The $19^{\text {th }}$ Annual Conference of the Association of Internet Researchers. Montréal, Canada: AolR. Retrieved from http://spir.aoir.org. 
attack the musical capacities, personality and masculinity of the performer and those who do are being reproached by fierce defenders. Despite the corporate capitalization on the free labor of these performers and the normative self-regulation of authenticity within social media spaces, Internet genres create potentialities where ordinary people are allowed to embody a fragility that acts as a vehicle for the embodiment of inclusive and queer masculinities.

\section{References}

Biddle, I. \& Jarman-Ivens, F. (2007) "Introduction: Oh Boy! Making Masculinity in Popular Music," in F. Jarman-Ivens \& I. Biddle (eds) Oh Boy! Masculinities and Popular Music, New York and Abingdon: Routledge, pp. 1-17.

Coates, N. (1997) "(R)Evolution Now? Rock and the Political Potential of Gender," in S. Whiteley (ed.) Sexing the Groove: Popular Music and Gender, Abingdon and New York: Routledge, pp. 50-64.

Connell, R.W. (2005) Masculinities, 2nd edn, Berkeley and Los Angeles: University of California Press.

Halberstam, J. (2007) "Keeping Time with Lesbians on Ecstasy," Women and Music: A Journal of Gender and Culture, 11: 51-58.

Kavoori, A. (2011) Reading YouTube: The Critical Viewers Guide, New York: Peter Lang.

Plasketes, G. (2005) "Re-flections on the Cover Age: A Collage of Continuous Coverage in Popular Music," Popular Music and Society, 28(2): 137-161.

Taylor, J. (2012) Playing it Queer: Popular Music, Identity and Queer World-Making, Bern: Peter Lang.

Van Dijck, J. (2013) “You Have One Identity': Performing the Self on Facebook and Linkedln," Media, Culture \& Society, 35(2): 199-215.

Dhaenens, F. (2018, October 10-13). (Un)covering masculinities in cover song videos. Paper presented at AolR 2018: The $19^{\text {th }}$ Annual Conference of the Association of Internet Researchers. Montréal, Canada: AolR. Retrieved from http://spir.aoir.org. 